BMJ Open Sport \& Exercise Medicine

\title{
Knee arthroplasty: a window of opportunity to improve physical activity in daily life, sports and work
}

\author{
Pieter Coenen (D) , ${ }^{1}$ Carlien Straat, ${ }^{1,2}$ P Paul Kuijer ${ }^{2}$
}

To cite: Coenen P, Straat C, Kuijer PP. Knee arthroplasty: a window of opportunity to improve physical activity in daily life, sports and work. BMJ Open Sport \& Exercise Medicine 2020;6:e000822. doi:10.1136/ bmjsem-2020-000822

Accepted 11 May 2020

\section{SLinked}

- http://dx.doi.org/10.1136/ bmjsem-2019-000729

\section{Check for updates}

(C) Author(s) (or their employer(s)) 2020. Re-use permitted under CC BY-NC. No commercial re-use. See rights and permissions. Published by BMJ.

${ }^{1}$ Amsterdam UMC, Vrije Universiteit Amsterdam, Department of Public and Occupational Health, Amsterdam Public Health Research Institute, Amsterdam, The Netherlands ${ }^{2}$ Amsterdam UMC, University of Amsterdam, Coronel Institute of Occupational Health, Amsterdam Public Health Research Institute, Amsterdam Movement Sciences Research Institute, Amsterdam, The Netherlands

Correspondence to Dr Pieter Coenen; p.coenen@amsterdamumc.nl

\section{KNEE ARTHROPLASTY IS AN ISSUE FOR MANY AND SOCIETAL PARTICIPATION AFTER SURGERY IS IMPORTANT}

Unicompartmental and total knee arthroplasty are well established treatment options, primarily aimed at reducing pain and improving joint function for patients with end-stage knee osteoarthritis. ${ }^{1}$ Although most patients receiving knee arthroplasty have good clinical outcomes, core outcome definitions suggest that societal participation after surgery is not a primary treatment goal. ${ }^{2}$ This is unfortunate as the number of patients receiving arthroplasty is rapidly increasing. In the Netherlands, a 297\% growth in knee arthroplasties is expected between 2005 and $2030,{ }^{3}$ with half of the patients of working age due the rising pension age and increasing trends in osteoarthritis among younger people. In particular for these 'younger' patients, societal participation including activities of daily life, sport and work is essential. $^{4}$

\section{KNEE ARTHROPLASTY MAY IMPROVE PHYSICAL ACTIVITY AND SPORTS PARTICIPATION}

In BMJ Open Sport Eै Exercise Medicine, Konings and colleagues ${ }^{5}$ reported on a systematic review on 19 studies ( $\mathrm{n}=4074$ participants) on physical activity and sports participation before and after knee arthroplasty. The authors found that knee arthroplasty, in general, has positive effects on physical activity and sports participation. Physical activity and sports participation return to levels similar to those before the osteoarthritis symptoms and is fortunately much higher compared with presurgery. Only high-impact sports were less frequently resumed after surgery. Furthermore, patients who remained active until the surgery were also most active after surgery, while patients who stopped participating in physical activities and sports prior to surgery were less likely to restart postsurgery.

\section{THE IMPORTANCE OF PHYSICAL ACTIVITY AND OTHER FORMS OF SOCIETAL PARTICIPATION}

Physical activity is a well-established contributor to longevity and good health. In various initiatives, including national and international guidelines, regular engagement in physical activity has been advocated for all, including for people with disabilities. ${ }^{6}$ In this light, the results of Konings and colleagues ${ }^{5}$ are encouraging, as they show that knee arthroplasty provides patients with a renewed possibility to engage in more physical activity and sports than they did presurgery.

Apart from engaging in physical activity and sports, also other forms of societal participation are of great importance for knee arthroplasty patients. Participation in daily activities such as work, but also other social and family activities, is highly relevant for many knee arthroplasty patients, as inability to participate in society has a significant negative impact on their quality of life. ${ }^{7}$

\section{A WINDOW OF OPPORTUNITY TO IMPROVE MORE THAN ONLY PHYSICAL ACTIVITY}

Konings and colleagues ${ }^{5}$ concluded that 'to achieve the full benefits out of knee arthroplasty, clinical guidelines and strategies aimed to keep patients capable and motivated to participate in sport activities until close before and after surgery are warranted'. In other words, with adequate guidance, knee arthroplasty provides a window of opportunity to improve physical activity in sports, daily life and work. Such guidance is in line with the Exercise is Medicine principle $^{8}$ that advocates better integration of physical activity advice in clinical practices. Despite the window of opportunity provided, however, better implementation of Exercise is Medicine is needed. Hence, more knowledge is required regarding when, how much and in what way we can best guide knee arthroplasty patients to increase their physical activity. 


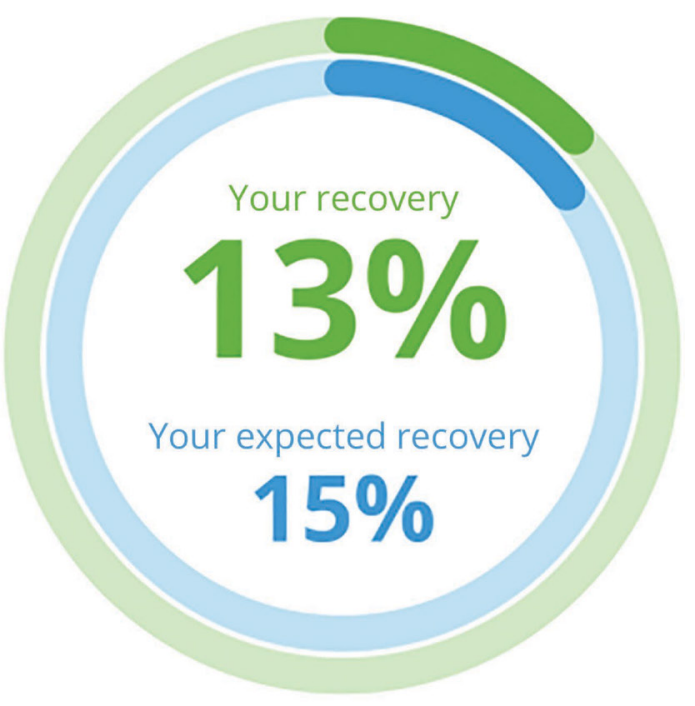

Activities you can resume next week

-Walking for 60 minutes

- Cycling for 30 minutes

- Lifting and/or carrying $5 \mathrm{~kg}$

Your total step count per day

Your daily step goal: 6000 steps per day Number of steps per day

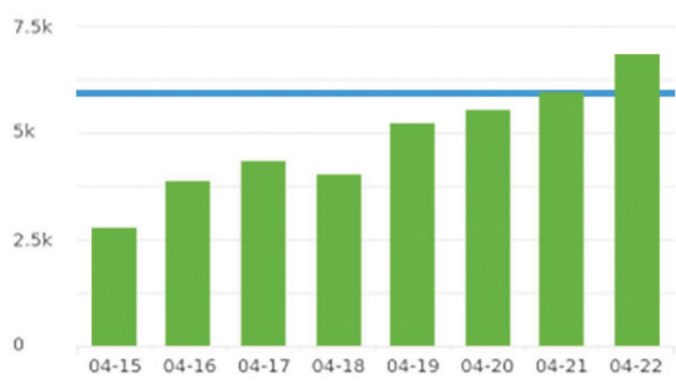

Figure 1 An example of a dashboard of an eHealth portal, providing knee arthroplasty patients tailored guidance on resumption of physical activity after surgery. Guidance on the resumption of activities and the recovery status of these activities (upper two panels) can be provided, while wearable devices can be used to provide patients with feedback on their physical activities, helping them to work towards selfchosen goals. This example is based on the IkHerstel app that has been evaluated for other patient populations ${ }^{13}$ and is currently being adapted for knee arthroplasty patients.

\section{Towards a more active life after knee arthroplasty}

An important limiting factor may be reluctance of clinicians to advise knee arthroplasty patients to be highly physically active due to a fear of an increased risk of revision surgery. This fear seems unnecessary, as a recent study showed that this risk of revision surgery is even reduced in patients with high levels of physical activity after knee arthroplasty. ${ }^{9}$ Nonetheless, more data on the long-term effect of physical activity on implant survival are needed.
Second, no consensus exists about how much physical activity should and can be prescribed to knee arthroplasty patients. Dutch healthcare professionals provide no or highly variable advice regarding recovery for daily activities after knee arthroplasty. ${ }^{10}$ For example, recommendations when to resume walking without crutches varied, if given at all, from 4 to 12 weeks postsurgery. Welldefined multidisciplinary recovery recommendations for resumption of physical activities are therefore needed to set realistic recovery expectations. These guidelines can, among others, be based on evidence provided by Konings and colleagues. ${ }^{5}$ Unfortunately, evidence in this review was based on self-reports of physical activity and sports, while more information from device-based measurements of those activities is needed.

Finally, it is unclear what the best way of providing guidance regarding physical activity for sports, daily life and work would be. A systematic review published in 2018 showed that, at that time, there were zero interventions regarding activity-based rehabilitation for return to work or sports after knee arthroplasty. ${ }^{11}$ A more recently published study showed that an intervention in which patients worked towards self-chosen activity goals together with a physical therapist lead to statistically significant more physical activity than with usual care, although only $9 \mathrm{~min} /$ day. ${ }^{12}$ These interventions may be promising. However, a limiting factor in the implementation of these interventions may be the finite amount of time a healthcare professional can spend on each patient. eHealth programmes could effectively replace healthcare professionals' tasks and provide daily patient-specific guidance regarding physical activity in daily life, sports and work, as we can learn from other types of surgery. ${ }^{13}$ Given the pressing demands on healthcare systems, such eHealth tools can be promising to be able to provide sustainable participation-based care in the future (figure 1).

\section{CONCLUSION}

An mounting amount of evidence, including the review by Konings and colleagues, ${ }^{5}$ suggests that knee arthroplasty provides a window of opportunity to improve physical activity. As the number of 'younger' knee arthroplasty patients will likely rise in coming years, this opportunity should be taken to provide better participation-based care. Promising interventions should be multidisciplinary in nature and evidence-based. Examples include the Exercise is Medicine recovery recommendations, patientspecific activity-based goal setting and eHealth initiatives providing knee arthroplasty patients with tailored advice to support more physical activity for sport and in daily life and work.

Acknowledgements We would like to thank Paul Sprangers (Interactive Studios) and Jeroen de Wilde (IkHerstel BV) for providing the figure, depicting a screenshot of the lkHerstel app that is currently under development. Permission to use this figure has been provided.

Contributors The three authors collectively drafted and reviewed the manuscript for important intellectual content. 
Funding This research was funded by The Netherlands Organisation for Health Research and Development, ZonMW (grant number 852001929).

Competing interests None declared.

Patient consent for publication Not required.

Provenance and peer review Commissioned; externally peer reviewed.

Open access This is an open access article distributed in accordance with the Creative Commons Attribution Non Commercial (CC BY-NC 4.0) license, which permits others to distribute, remix, adapt, build upon this work non-commercially, and license their derivative works on different terms, provided the original work is properly cited, appropriate credit is given, any changes made indicated, and the use is non-commercial. See: http://creativecommons.org/licenses/by-nc/4.0/.

ORCID iD

Pieter Coenen http://orcid.org/0000-0002-4034-7063

\section{REFERENCES}

1 Carr AJ, Robertsson O, Graves S, et al. Knee replacement. Lancet 2012;379:1331-40.

2 Singh JA, Dowsey MM, Dohm M, et al. Achieving consensus on total joint replacement trial outcome reporting using the OMERACT filter: endorsement of the final core domain set for total hip and total knee replacement trials for endstage arthritis. J Rheumatol 2017:44:1723-6.

3 Otten R, van Roermund PM, Picavet HSJ. [Trends in the number of knee and hip arthroplasties: considerably more knee and hip prostheses due to osteoarthritis in 2030]. Ned Tijdschr Geneeskd 2010;154:A1534.
4 Witjes S, van Geenen RCl, Koenraadt KLM, et al. Expectations of younger patients concerning activities after knee arthroplasty: are we asking the right questions? Qual Life Res 2017;26:403-17.

5 Konings MJ, De Vroey H, Weygers I, et al. The effect of knee arthroplasty on sports participation and activity levels: a systematic review and meta-analysis. BMJ Open Sport Exerc Med. In Press.

6 World Health Organization. Global recommendations on physical activity for health. Geneva, Switzerland: World Health Organization, 2010.

7 Ackerman IN, Bucknill A, Page RS, et al. The substantial personal burden experienced by younger people with hip or knee osteoarthritis. Osteoarthritis Cartilage 2015;23:1276-84.

8 Berra K, Rippe J, Manson JE. Making physical activity counseling a priority in clinical practice: the time for action is now. JAMA 2015;314:2617-8.

9 Crawford DA, Adams JB, Hobbs GR, et al. Higher activity level following total knee arthroplasty is not deleterious to mid-term implant survivorship. J Arthroplasty 2020;35:116-20.

10 Straat C, Kuijer PP, Coenen P. [Varying advises about return to work and daily activities after a knee replacement surgery in Dutch hospitals]. In: Bedrijfsgeneeskundige dagen. Arnhem, The Netherlands, 2019

11 Kuijer PPFM, van Haeren MM, Daams JG, et al. Better return to work and sports after knee arthroplasty rehabilitation? Occup Med 2018;68:626-30.

12 Hoorntje A, Witjes S, Kuijer PPFM, et al. Does activity-based rehabilitation with goal attainment scaling increase physical activity among younger knee arthroplasty patients? Results from the randomized controlled ACTION trial. J Arthroplasty 2020;35:706-11.

13 van der Meij E, Anema JR, Leclercq WKG, et al. Personalised perioperative care by e-health after intermediate-grade abdominal surgery: a multicentre, single-blind, randomised, placebo-controlled trial. Lancet 2018;392:51-9. 


\section{Correction: Knee arthroplasty: a window of opportunity to improve physical activity in daily life, sports and work}

Coenen P, Straat C, Kuijer PP. Knee arthroplasty: a window of opportunity to improve physical activity in daily life, sports and work. BMJ Open Sport \& Exercise Medicine 2020;6:e00822. doi: 10.1136/bmjsem-2020-000822

This article has been corrected since it was published online. The funding statement has been updated to: This research was funded by The Netherlands Organisation for Health Research and Development, ZonMW (grant number 852001929).

(c) Author(s) (or their employer(s)) 2020. Re-use permitted under CC BY-NC. No commercial re-use. See rights and permissions. Published by BMJ.

This is an open access article distributed in accordance with the Creative Commons Attribution Non Commercial (CC BY-NC 4.0) license, which permits others to distribute, remix, adapt, build upon this work non-commercially, and license their derivative works on different terms, provided the original work is properly cited, appropriate credit is given, any changes made indicated, and the use is non-commercial. See: http://creativecommons.org/licenses/by-nc/4.0/.

BMJ Open Sp Ex Med 2020;6:e000822corr1. doi:10.1136/bmjsem-2020-000822corr1

D) Check for updates 